\title{
Phylogenetic diversity and community structure of sponge-associated bacteria from mangroves of the Caribbean Sea
}

\author{
Jiangke Yang ${ }^{1}$, Jin Sun ${ }^{2}$, On On Lee ${ }^{1}$, Yim Him Wong ${ }^{1}$, Pei Yuan Qian ${ }^{1, *}$ \\ ${ }^{1}$ KAUST Global Collaborative Research Program, Department of Biology, Hong Kong University of Science and Technology, \\ Clear Water Bay, Kowloon, Hong Kong SAR \\ ${ }^{2}$ Department of Biology, Hong Kong Baptist University, Hong Kong SAR
}

\begin{abstract}
To gain insight into the species richness and phylogeny of the microbial communities associated with sponges in mangroves, we performed an extensive phylogenetic analysis, based on terminal restriction fragment length polymorphism profiling and $16 \mathrm{~S}$ ribosomal RNA gene sequences, of the 4 sponge species Aplysina fulva, Haliclona hogarthi, Tedania ignis and Ircinia strobilina as well as of ambient seawater. The sponge-associated bacterial communities contained 13 phyla, including Poribacteria and an unclassified group not found in the ambient seawater community, $98 \%$ of which comprised Proteobacteria, Cyanobacteria and Bacteroidetes. Although the sponges themselves were phylogenetically distant and bacterial community variation within the host species was observed, microbial phyla such as Proteobacteria, Acidobacteria, Chloroflexi and the unclassified group were consistently observed as the dominant populations within the communities. The sponge-associated bacterial communities resident in the Caribbean Sea mangroves are phylogenetically similar but significantly distinct from communities found in other biogeographical sites such as the deep-water environments of the Caribbean Sea, the South China Sea and Australia. The interspecific variation within the host species and the distinct biogeographical characteristics that the sponge-associated bacteria exhibited indicate that the acquisition, establishment and formation of functional sponge-associated bacterial communities may initially be the product of both vertical and horizontal transmission, and is then shaped by the internal environment created by the sponge species and certain external environmental factors.
\end{abstract}

KEY WORDS: Sponge $\cdot$ Bacterial diversity $\cdot$ Community composition $\cdot 16 \mathrm{~S}$ rRNA $\cdot$ T-RFLP $\cdot$ Mangrove

\section{INTRODUCTION}

Sponge-associated microbial communities display high genetic diversity in which bacteria, archaea and microbial eukaryote phyla are all represented. Bacterial phyla are often the dominant group and comprise up to $40 \%$ of sponge biomass (Hentschel et al. 2003, 2006, Hill 2004). Up to now, 20 bacterial phyla, including a highly sponge-specific phylum, Poribacteria, have been detected in several sponges with a high microbial abundance (Fieseler et al. 2004, 2006, Lafi et al. 2009).

The association between microorganisms and sponges is often considered mutualistic. The sponge serves as a shelter for bacteria against grazers and offers a consistent nutrient supply. The bacteria, in turn, may be the biosynthetic originators of highly diverse bioactive compounds that defend the sponge against predation, microbial attachment and fouling (Faulkner et al. 2000, Thakur \& Müller 2005, Taylor et al. 2007b, Dash et al. 2009). Two mechanisms (environmental and vertical transmission) have been suggested to explain the establishment of the association between sponges and microbes. According to the environmental transmission hypothesis, sponge-associated microorganisms are present at a low abundance in the surrounding water and are selectively retained by the sponge. When the microbes encounter favorable conditions and outcompete other potential colonizers, they 
multiply and gradually establish themselves within the sponge mesohyl (Taylor et al. 2007a,b). The establishment of this relationship relies on mutual recognition between the sponge and its microbial partners, and also on physical competition among the microbial communities themselves (Wilkinson 1984, Müller \& Müller 2003, Müller et al. 2004). In accordance with this hypothesis, sponges inhabiting the same ecological niche tend to harbor similar microbial communities. The vertical transmission of specific microbes from parent to progeny in sponges is another mechanism that has been reported recently (Usher et al. 2001, Enticknap et al. 2006, Schmitt et al. 2007, 2008, Sharp et al. 2007, Lee et al. 2009). In this scenario, a sponge is colonized by an ancestral strain, and the microbes then evolve to become specific to that sponge, thereby exhibiting spatial and temporal stability. Thus, there may be consistent communities of sponge-associated bacteria not altered by changes of environment (Hentschel et al. 2002, Lee et al. 2006).

Recent surveys contradict the existence of a general uniform sponge-associated microbial community regardless of sponge species and location. Instead, the composition of a sponge-inhabiting microbial community depends on the host species and geographical origin (Taylor et al. 2004, 2005). Other evidence from the artificial culture of sponges suggests that the communities can change dramatically after a period of artificial culture (Mohamed et al. 2008a,b). Moreover, the effect of the adjustment capacity of the environment on the structure of bacterial communities suggests that the sponge-associated bacterial communities may shift with habitat or season, which would make it difficult to maintain a uniform community.

Marine sponges populate the Caribbean Sea in abundance and have a great potential to influence benthic and pelagic processes. In the present study, we collected 4 phylogenetically distinct sponge species from a mangrove area in Sweeting Cay, the Bahamas. After initial profiling by terminal restriction fragment length polymorphism (T-RFLP), we constructed the 16S rRNA gene clone libraries of the bacteria associated with these sponges and the ambient seawater to elucidate the magnitude of their diversity and phylogeny. The libraries were also used to test the dimension of community structure that is affected by the selective pressure of the environment and host species by comparing them with those from other regions.

\section{MATERIALS AND METHODS}

Sample collection and DNA extraction. Sponge tissues were collected at a depth of $1 \mathrm{~m}$ from a mangrove area in Sweetings Cay, the Bahamas $\left(26^{\circ} 36^{\prime} \mathrm{N}\right.$, $77^{\circ} 54^{\prime} \mathrm{W}$ ). Three individuals of each sponge species were brought to the water surface and immediately transported back to the laboratory on board the RV 'Seward Johnson' in sterile plastic bags containing in situ seawater. Upon arrival at the laboratory, the sponge tissues $(0.5 \mathrm{ml}$ each) were flushed with autoclaved $0.22 \mu \mathrm{m}$ filtered seawater to remove any loosely attached bacteria, cut into small pieces and then submerged in $0.8 \mathrm{ml}$ of extraction buffer $(100 \mathrm{mM}$ Tris$\mathrm{HCl}, 100 \mathrm{mM} \mathrm{Na}$-EDTA, $100 \mathrm{mM} \mathrm{Na} \mathrm{HPO}_{4}, 1.5 \mathrm{M}$ $\mathrm{NaCl}_{1} 1 \% \mathrm{CTAB}, \mathrm{pH}$ 8) for DNA extraction. Sponge specimens were identified on board based on the structure of spicules. The indigenous planktonic bacterial community in the surrounding seawater was collected in triplicate by filtering $1 \mathrm{l}$ of seawater through $0.22 \mu \mathrm{m}$ polycarbonate membranes (Osmonics). The membranes were then submerged in $0.8 \mathrm{ml}$ of extraction buffer for subsequent DNA extraction.

DNA extraction was conducted according to the description of Liu et al. (1997). DNA from replicated samples was further purified by using a Mo Bio soil DNA isolation kit (Mo Bio Laboratories). The quality and quantity of DNA were checked with a Nanodrop device (Nanodrop).

T-RFLP. Hexa-chloro derivative (HEX) labeled primers 26F (5'-HEX-AGA GTT TGA TCC TGG CTC AG-3') and 1055R (5'-CAC GAG CTG ACG ACA GCC AT-3'), corresponding to Escherichia coli 16S rRNA positions 26-45 and 1055-1074, respectively, were used for PCR amplification. Amplification was conducted with a Bio-Rad thermal cycler using the following cycling conditions: initial denaturation at $94^{\circ} \mathrm{C}$ for $5 \mathrm{~min} ; 26$ cycles at $94^{\circ} \mathrm{C}$ for $45 \mathrm{~s}, 55^{\circ} \mathrm{C}$ for $45 \mathrm{~s}$ and $72^{\circ} \mathrm{C}$ for $1 \mathrm{~min}$; and a final extension at $72^{\circ} \mathrm{C}$ for $6 \mathrm{~min}$.

Approximately $500 \mathrm{ng}$ of PCR products were digested with $10 \mathrm{U}$ of the restriction enzyme Msp I at $37^{\circ} \mathrm{C}$ for $6 \mathrm{~h}$, ethanol precipitated, and then the PCR products were resolved in $10 \mu \mathrm{l}$ water. Purified products $(10 \mu \mathrm{l})$ were mixed with $0.5 \mu \mathrm{l}$ of an internal size standard (ET-550R $;$ Amersham Biosciences), denatured at $95^{\circ} \mathrm{C}$ for $2 \mathrm{~min}$, snap-cooled on ice and subjected to a MegaBACE genetic analyzer (Amersham Biosciences) operating in the genotyping mode to generate the chromatography. After electrophoresis, the sizes of the fluorescently labeled terminal restriction fragments (TRFs) were determined by comparison with the size standard using Genetic Profiler (Amersham Biosciences). TRFs $<35$ and $>900 \mathrm{bp}$ in size were excluded from the statistical analysis to screen out background noise and inaccurate size determination.

Construction of the 16S rRNA gene clone libraries. PCR products amplified by primers $26 \mathrm{~F}$ and $1055 \mathrm{R}$ were purified by electrophoresis in a $1 \%(\mathrm{w} / \mathrm{v})$ agarose gel, and bands of approximately $1000 \mathrm{bp}$ were excised and recovered using a gel extraction kit (TianGen). 
The purified PCR products were cloned into a pCR2.1TOPO vector according to the manufacturer's instructions (Invitrogen). White colonies were randomly pricked out into a 96-well plate containing LB broth (100 $\mu \mathrm{g} \mathrm{ml}^{-1}$ ampicillin) and sequenced using a genetic sequencer (3730 DNA Analyzer, ABI) with M13F and M13R as the sequence primers.

After manually cutting off the vector sequences, the net sequences from both directions were aligned and compared with those in the database using the Basic Local Alignment Search Tool (BLAST) algorithm to identify known sequences with the highest degree of similarity. The sequences were examined for the formation of chimeras using the CHIMERA_CHECK program (Cole et al. 2003). All of the sequences recovered in the present study were deposited in GenBank (accession numbers GU981764-GU982186).

Estimation of microbial diversity and statistical analysis of clone libraries. The DOTUR (distancebased OTU and richness) program was used to assign sequences to operational taxonomic units (OTUs) at different dissimilarity levels and to calculate collector's curves for the observed unique OTUs, bias-corrected Chao1, the abundance-base coverage estimator (ACE), and the Shannon $(H)$ and Simpson indices $(D)$ of diversity (Schloss \& Handelsman 2005). Representative sequences were randomly picked from each OTU determined at a 2 or $8 \%$ dissimilarity level and assigned to phylogenetic affiliations and taxonomic assays.

To evaluate the relatedness of our sequences and the reference sequences (Table 1), the sequences were initially trimmed so that the same regions were compared; fragments approximately $550 \mathrm{bp}$ in length were then aligned using the ClustalX program (Thompson et al.
1997) and the alignments were exported to the PHYLIP 3.5 software package. Phylogenetic analyses using neighbor-joining methods were carried out. Bootstrap analysis was performed on 100 samplings of the sequence alignment using the SEQBOOT program in PHYLIP, and only values of $>50 \%$ were included in the trees.

The similarity among the bacterial communities in our samples was determined using weighted UniFrac environmental clustering and principal component analyses (PCA) (Lozupone \& Knight 2005, Lozupone et al. 2007). The phylogeny tree generated by aligning the $550 \mathrm{bp}$ length of 16S rRNA gene fragments of our samples and the reference communities was regarded as the input phylogeny file, and the sponge species origin and geographical location of these sequences were defined as the environmental files. The number of sequences in each OTU was regarded as the weight. The online UniFrac program (http://bmf.colorado.edu/unifrac/ index.psp) takes the molecular evolutionary distances of sequences and their environmental occurrence to analyze the similarity of microbial communities.

\section{RESULTS}

\section{T-RFLP analysis}

The T-RFLP analysis revealed that the patterns and number of TRFs derived from the ambient seawater was distinctly different from those from the sponge communities (Fig. 1). Similar results were obtained from the cluster analysis, which grouped the bacterial communities obtained from the sponges and the seawater into 2 distinct groups (Fig. 2). The differences

Table 1. Samples collected in the present study and source of sequence data from other studies for comparison

\begin{tabular}{|llllcl}
\hline $\begin{array}{l}\text { Sample } \\
\text { ID }\end{array}$ & Sample source & Geographical origin & GenBank accession no. & Source \\
\hline W & Seawater & & & \\
AF & Aplysina fulva & Mangrove, Sweetings Cay, the Bahamas & GU981764-GU981851 & Present study \\
HH & Haliclona hogarthi & Mangrove, Sweetings Cay, the Bahamas & GU982024-GU982106 & Present study \\
IS & Ircinia strobilina & Mangrove, Sweetings Cay, the Bahamas & GU981852-GU981939 & Present study \\
TI & Tedania ignis & Mangrove, Sweetings Cay, the Bahamas & GU982107-GU982186 & Present study \\
PC & Polymastia cf. corticata & 1127 m depth, Kahouanne Basin, & GU005553-EU005595 & Meyer \& Kuever \\
& & Caribbean Sea & & $(2008)$ \\
SZ & Svenzea zeai & San Salvador Island, the Bahamas & FJ529257-FJ529310 & Lee et al. (2009) \\
AR & Agelas robusta & Nansha Islands, South China Sea, China & GQ215663-GQ215694 & GenBank \\
DA & Dysidea avara & South China Sea, China & DQ274111-DQ274154 & GenBank \\
GC & Gelliodes carnosa & Hainan Island, South China Sea & FJ937832-FJ937871 & GenBank \\
HS & Haliclona simulans & South China Sea, China & FJ999553-FJ999622 & GenBank \\
CC & Cymbastela concentrica & New South Wales, Sydney, Australia & AY942753-AY942781 & GenBank \\
RO-I & Rhopaloeides odorabile & Pelorus Island, North Queensland, Australia & EU183744-EU184009 & Webster et al. \\
& & & & $(2008)$ \\
RO-II & Rhopaloeides odorabile & Davies Reef, Great Barrier Reef, Australia & AF333519-AF333552 & Webster et al. \\
& & & & $(2001)$ \\
\hline
\end{tabular}


between the sponge and seawater communities were further supported by ANOSIM, with a significant $\mathrm{R}$-value of 0.85 . The bacterial communities derived from the sponges were further divided into 2 subgroups, one comprising the samples from Ircinia strobilina and Tedania ignis and the other comprising those from Haliclona hogarthi and Aplysina fulva (Fig. 2).

\section{Bacterial diversity and community structure}

From the five 16S rRNA gene libraries, 480 clones were screened and sequenced. After sequence picking, assembling and chimera checking, 427 clones with an average length of $1000 \mathrm{bp}$ remained. These clones, at a similarity level of $92 \%$, were assigned to
201 OTUs (Table 2). The diversity indices indicated that the indigenous bacterial community in the seawater was less diverse than those associated with the sponges, whereas the bacterial community in the sponge Tedania ignis showed the highest Chao1 (121.5) and ACE (137.6) values (Table 2).

By comparing the sequences of our clones with those deposited in GenBank and the ribosomal RNA database (Cole et al. 2003), the OTUs recovered were classified into 12 known phyla - Acidobacteria, Actinobacteria, Bacteroidetes, Chloroflexi, Cyanobacteria, DeinococcusThermus, Firmicutes, Nitrospirae, Poribacteria, Proteobacteria, Spirochaetes and Verrucomicrobia - and 1 unclassified phyla (Fig. 3). The bacterioplankton community in the ambient seawater was composed of 7 phyla, of which Alphaproteobacteria (37.7\%), Gamma-

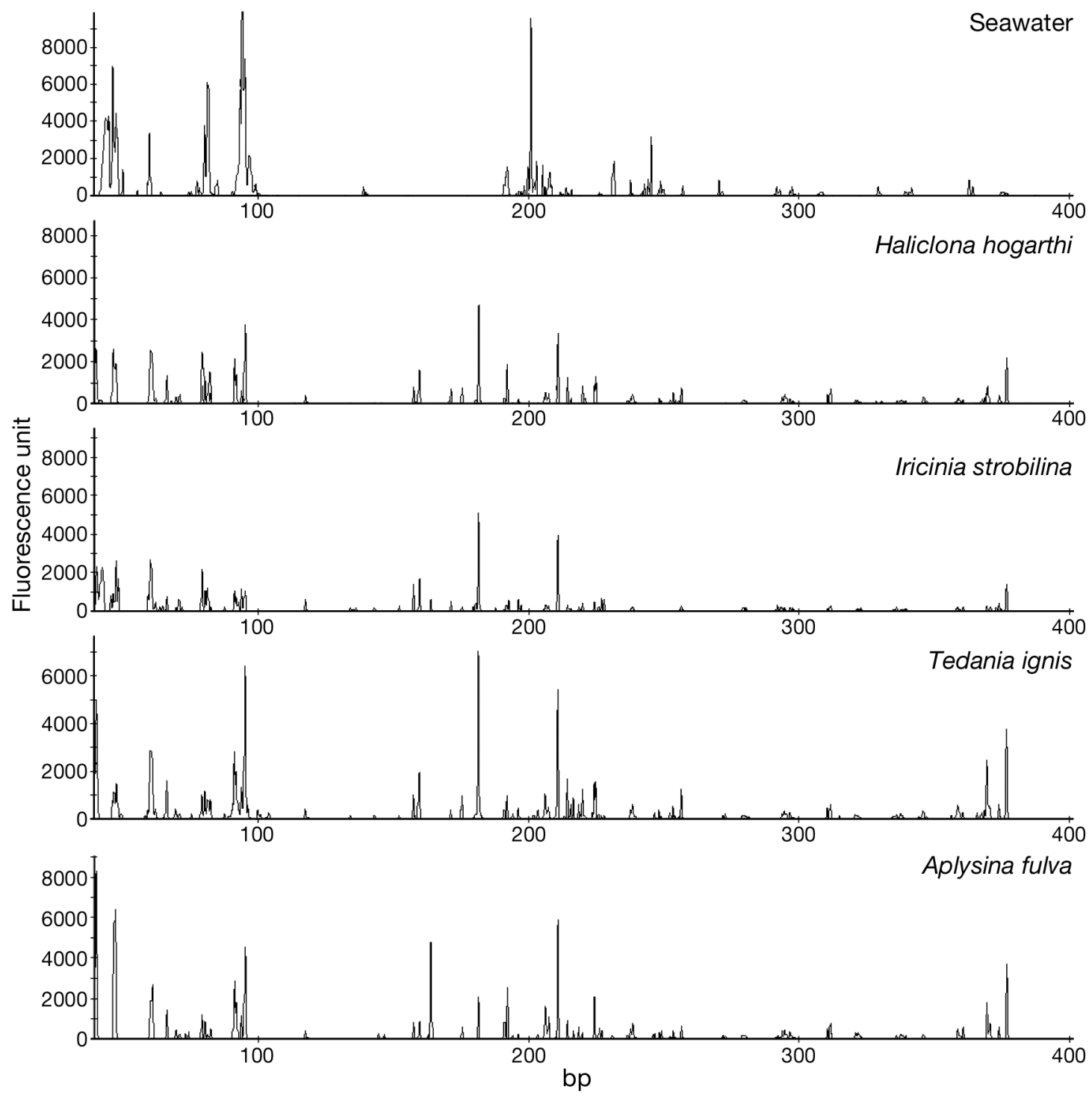

Fig. 1. Representative electropherograms of terminal restriction fragments derived from MspI digestion of PCR-amplified bacterial community 16S rRNA genes obtained from the sponges and ambient seawater 
proteobacteria (23.6\%) and Bacteroidetes (22.5\%) were the most dominant groups. The bacterial communities associated with the sponges consisted of 13 groups and were generally dominated by Proteobacteria (20.1 to 53.2\%), Chloroflexi (13.6 to $18.3 \%$ ) and Acidobacteria (3.2 to $6.7 \%$ ). Bacteroidetes, which are known to exist in seawater, were absent from the sponge samples. Poribacteria, which are suggested to be sponge-specific, were recovered in two of the sponge samples in small proportions $(1.2 \%)$, but not in the seawater sample.

\section{Phylogenetic analysis of bacterial communities}

Neighbor-joining trees were constructed based on the evolutionary distance of our 16S rRNA gene

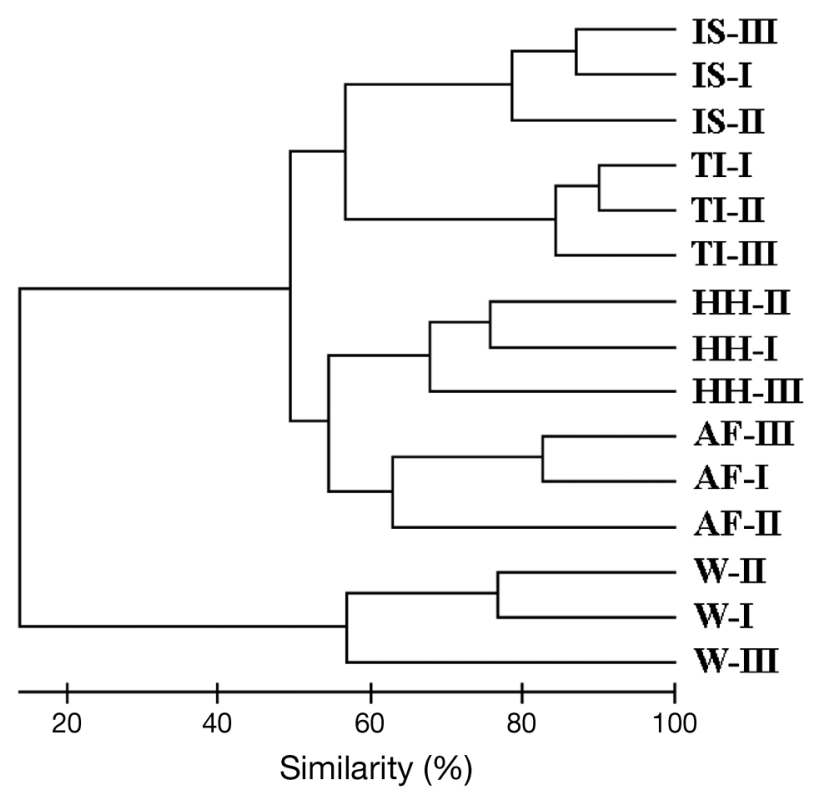

Fig. 2. Cluster analysis based on the terminal restriction fragments of the sponge- and seawater-derived communities. IS: Ircinia strobilina; TI: Tedania ignis; HH: Haliclona hogarthi; AF: Aplysina fulva; W: seawater. Three replicates (I-III) were included for each sample

Table 2. Diversity analysis of the 16S rRNA gene clone libraries constructed for the sponge and seawater samples. A similarity level of $92 \%$ was used to differentiate different operational taxonomic units (OTUs). Chao1: bias-corrected estimator; ACE: abundance-base coverage estimator

\begin{tabular}{|lccccrr|}
\hline Source & $\begin{array}{r}\text { No. of } \\
\text { clones }\end{array}$ & $\begin{array}{r}\text { No. of } \\
\text { OTUs }\end{array}$ & $\begin{array}{c}\text { Simpson } \\
\text { index }\end{array}$ & $\begin{array}{c}\text { Shannon } \\
\text { index }\end{array}$ & Chao1 & ACE \\
\hline Seawater & 89 & 34 & 0.045 & 3.13 & 47.7 & 70.7 \\
Haliclona hogarthi & 88 & 45 & 0.028 & 3.55 & 74.6 & 92.2 \\
Ircinia strobilina & 82 & 43 & 0.026 & 3.53 & 64.2 & 83.5 \\
Tedania ignis & 84 & 44 & 0.034 & 3.45 & 121.5 & 137.6 \\
Aplysina fulva & 84 & 35 & 0.042 & 3.21 & 62.1 & 71.9 \\
\hline
\end{tabular}

sequences and the reference sequences retrieved from other locations (Fig. 4). Among the 14 phyla represented in our sequences, Proteobacteria was the most dominant phylum, and was divided into the Alpha-, Gamma- and Deltaproteobacteria subgroups. Clones belonging to Alphaproteobacteria were further divided into 7 clusters ( $\alpha$-Pro-I to -VII), and clones belonging to Gamma- and Deltaproteobacteria were further divided into 5 and 3 subgroups, respectively (see Fig. S1A,S1B in Supplement 1, available at www. int-res.com/articles/suppl/a062p231_supp.pdf). None of the seawater-derived sequences belonged to Deltaproteobacteria, and the main group of this subdivision contained sequences from our own sponge samples and another Caribbean Sea sponge, Svenzea zeai.

Chloroflexi was uniformly present in all of the 4 bacterial communities in the sponges but was completely absent from that of seawater (Fig. S1C). Similar to the Chloroflexi tree, the Acidobacteria tree was solely composed of clones from our sponge species, but not any of the seawater-derived clones. This tree was further divided into 3 subgroups (Aci-I to -III) and was phylogenetically close to the Svenzea zeaiderived clones (Fig. S1D). The Actinobacteria and Cyanobacteria trees consisted of a mixture of both sponge and seawater clones.

One unclassified group was detected in our samples. The clones in these groups were distant from the other phyla, and had a sequence divergency from recognized clones of more than $50 \%$. Clones from this group were similar to a clone derived from gas hydrate sediment, which suggests that this unclassified group plays a role in the anaerobic metabolism of carbon.

\section{Sponge bacterial community distribution in response to host and biogeography}

Weighted PCA was conducted on the bacterial communities in different host species and from different geographical sources to elucidate the relationship between bacterial communities (Table 1, Fig. 5). UniFrac environmental clustering of the $16 \mathrm{~S}$ rRNA gene clone libraries clearly grouped 4 sponge-associated communities from the present study with that associated with the Caribbean sponge Svenzea zeai, whereas these communities were remarkably different from those in the ambient seawater and the Caribbean Sea deepwater sponge Polymastia cf. corticata (Fig. 5A). The communities associated with sponges of the same geo- 


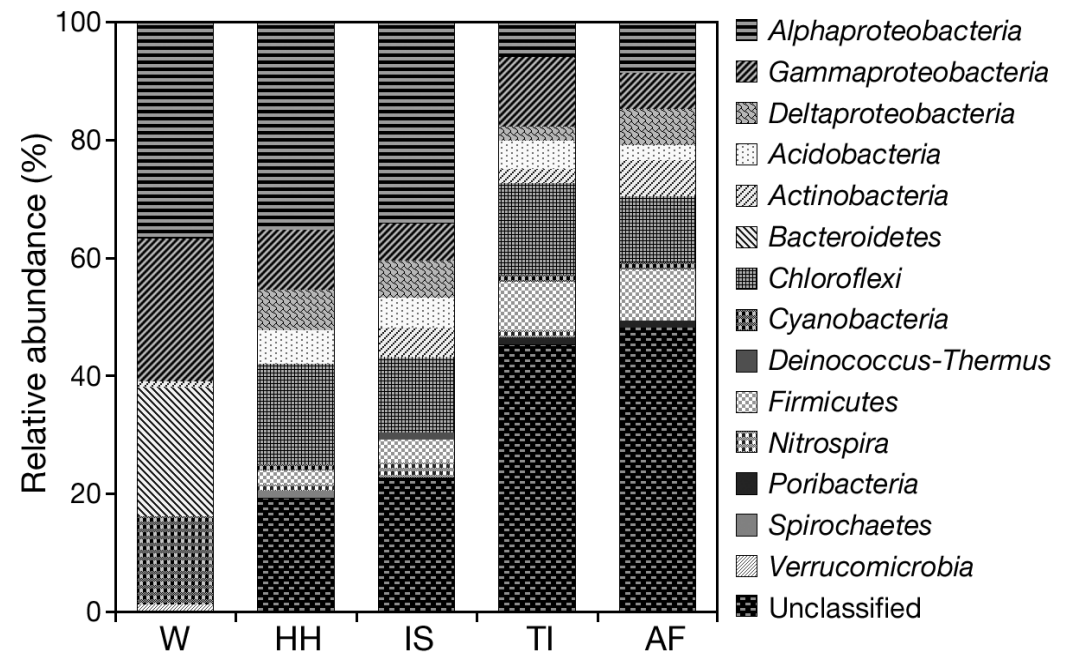

Fig. 3. Phylogenetic affiliations of the operational taxonomic units (OTUs) derived from the seawater and sponge samples. OTUs were classified as having a similarity level of $92 \%$. Data shown are the percentages of identifiable hits. W: seawater; HH: Haliclona hogarthi; IS: Ircinia strobilina; TI: Tedania ignis; AF: Aplysina fulva

graphic locations-e.g. the Caribbean Sea, the South China Sea and Australia - tended to cluster together, although the sponge hosts were phylogenetically distant (Fig. 5B).

\section{DISCUSSION}

The 16S rRNA gene-based diversity analysis revealed that the bacterial communities associated with 4 mangrove sponges collected from the Caribbean Sea were composed of representatives from 12 known bacterial phyla and 1 unclassified clade. This unclassified group was clustered with the reference sequences from gas hydrate sediment-derived clones. It is speculated that these clones play a role in the anaerobic metabolism of carbon nutrients. We believe that further studies using measures such as metagenomics would elucidate their functional role. Our sponge-derived bacterial communities are more phylogenetically complex and diverse than those reported from deep-sea and shallow-water sponge species using the same method (Friedrich et al. 2001, Meyer \& Kuever 2008, Hardoim et al. 2009). Certainly, the magnitude of diversity revealed by this $16 \mathrm{~S}$ rRNA clone library method is not as large as that generated by $16 \mathrm{~S}$ rRNA gene tag pyrosequencing (Webster et al. 2010), but our clone libraries also captured the majority of the sequence types in the samples. Moreover, in our libraries, each clone contains a 1000 bp 16S rRNA gene fragment, which supplied more phylogeny information than that generated by pyrosequencing (50 to $60 \mathrm{bp}$ per read) (Webster et al. 2010).

Different phyla of bacteria found in sponges may benefit their hosts in different ways. For instance, sponge-associated Actinobacteria and Deltaproteobacteria are known to produce prolific secondary metabolites and may contribute to the chemical defense mechanisms of their host sponges against predators and biofouling (Schmidt et al. 2000, Schirmer et al. 2005). Although some studies of Alpha- and Gammaproteobacteria have suggested that they may have derived from free-living, opportunistic populations and that they have no benefit to the host (Meyer \& Kuever 2008), other evidence suggests that strains of Gammaproteobacteria, such as Pseudoalteromonas and Alteromonas, produce a variety of bioactive compounds that benefit their hosts (McCarthy et al. 1994, Egan et al. 2001, Holmström et al. 2002). Chloroflexi is another dominant group found in the sponge mesohyl. It is believed that this phylum plays an important role in $\mathrm{CO}_{2}$ fixation and in the balance of the carbon cycle in the anaerobic internal environment of sponges (Zarzycki et al. 2009).

Although several phylogenetic surveys have demonstrated that the microbial communities associated with different sponge species are highly diverse even if the sponge hosts came from the same habitat (Taylor et al. $2004,2005)$, some reports have shown a certain degree of uniformity among microbial communities from taxonomically and geographically separated sponges (Hentschel et al. 2002, 2006, Lee et al. 2006). In the present study, similar bacterial communities were detected among the 4 sponges investigated. Gammaproteobacteria, Deltaproteobacteria, Acidobacteria and Chloroflexi were found in all of the sponge species in the present study, although the hosts were phylogenetically distant. Contradictory to the argument of a uniform microbial signature of sponges across spatial

Fig. 4. Rooted neighbor-joining phylogenetic trees showing the relatedness of our sequences with other deposited sequences in GenBank. Clones were retrieved from seawater (W) and the sponges Haliclona hogarthi (HH), Aplysina fulva (AF), Ircinia strobilina (IS) and Tedania ignis (TI). The polygons represent operational taxonomic units (OTUs) that are $>80 \%$ similar, and the number of clones that each OTU contains is given in parentheses. Bootstrap confidence values $>50 \%$ are shown at the nodes. Methanococcus maripaludis was used as an outgroup. Scale bar $=0.05$ substitutions per nucleotide position 

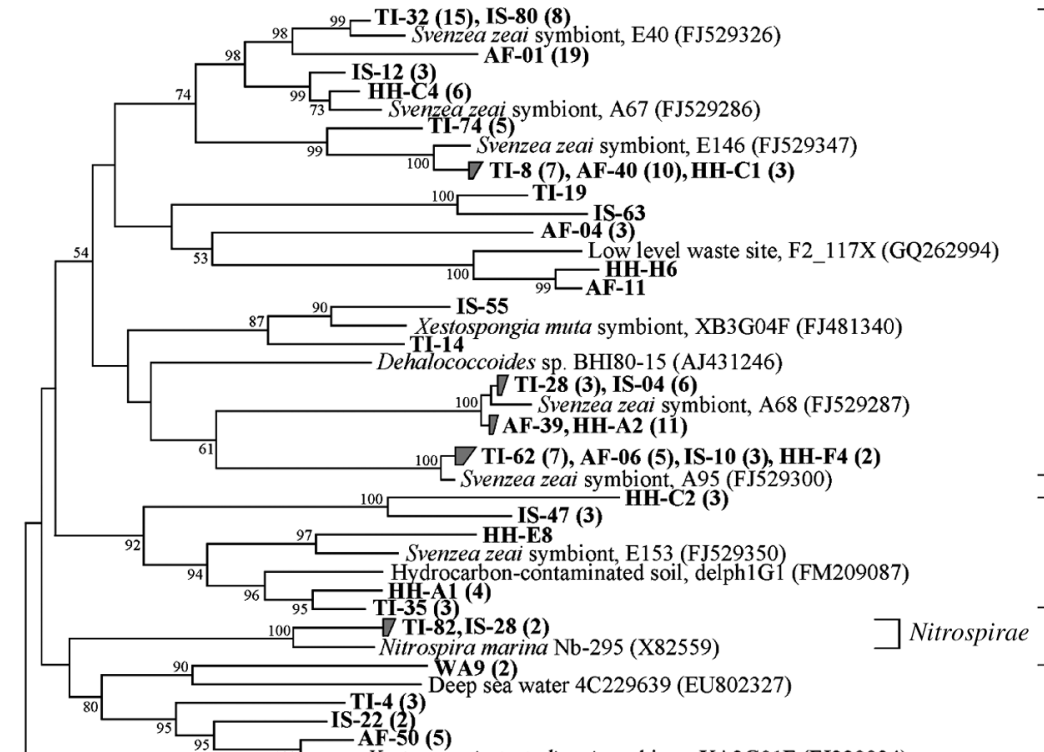
AF-50 (5)

${ }_{100}$ Xestospongia testudinari symbiont, XA2G01F (FJ229924)

100 TI-33

zeai symia testudinari symbiont, XA2G01F (FJ229924)
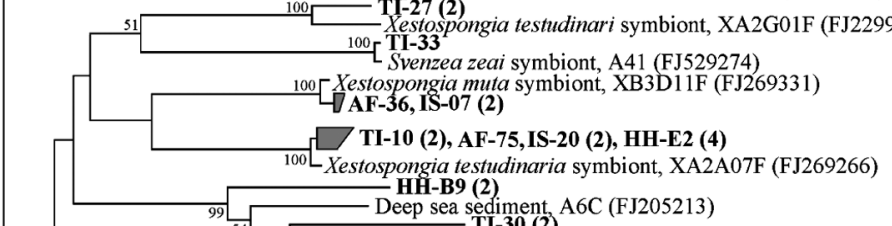

Deep sea (2)

${ }_{54}{ }_{68} \square$ Montastraea foveolata symbiont, Mfav_O17 (GU118537)

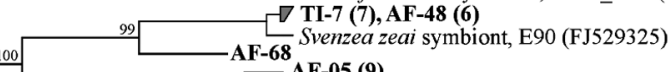

AF-05 (9) symbiont, PK019 (EF076072)

다 TI-58 (6), IS-19 (5), HH-B4 (6)

98 - AF-07, HH-D12 (3)

Svenzea zeai symbiont TA71 (FJ529289)

Syenzea zeai symbiont, A17 (FJ529264)

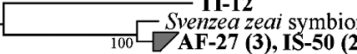

100 DAF-19, IS-33, HH-G4

(EF076130)

Agelas dilatata symbiont, AD027 (EF076130)
Desulfomonile limimaris DCB-F (AF282177)
$100 \square$ AFenzea zeai symbiont, A102 (FJ529303)

Bxinella corrugata symbiont,MBrad_A7(EF092260)

99 $\square$ TI-29 (7), AF-16 (4), HH-B10 (6)

AF-42

Pseudomon

- IS-31 (4)

21)

WA10 (10)

Rhodovulum strictum JCM 9221 (AB079635)

AF-08 (7), HH-B2 (8), HH-B8 (16)

IS-01 (18)

Svenzea zeai symbiont, A51 (FJ529294)

—-Sea water, ZA3318c (AF382114)

58 68 Montastraea faveolata symbiont, Mfav_B20 (GU118617)

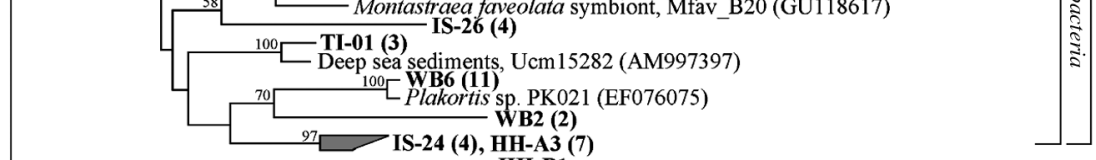

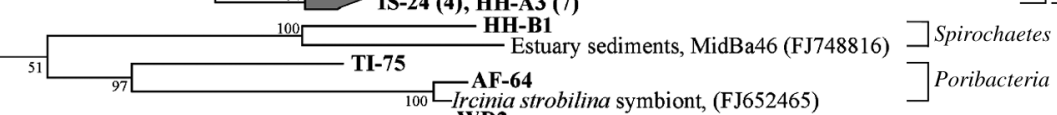

${ }_{100} \square$ Fucophilus fucoidanolyticus SI-1234 (AB073978) $\square$ Verrucomicrobia

$100 \square$ Ochrosphaera neapolitan plastid, CCMP 593 (X80390)
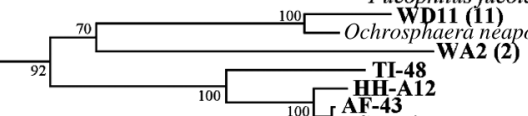

${ }_{100}^{10}$ L AF-43

IS- Synechococcus spongiarum 621SC1 (EF656442)

${ }_{100}^{100}$ AF-43
IS-08
Truepera radiovictrix strain TU-8 (DQ022077) $\square$ Deinococcus-Thermus

$9 5 \longdiv { 1 0 0 }$ [ WD1 (2) ${ }_{\text {Sea water } 1 \text { 1C227769 (EU800071) }}$

WDi2 (12) 

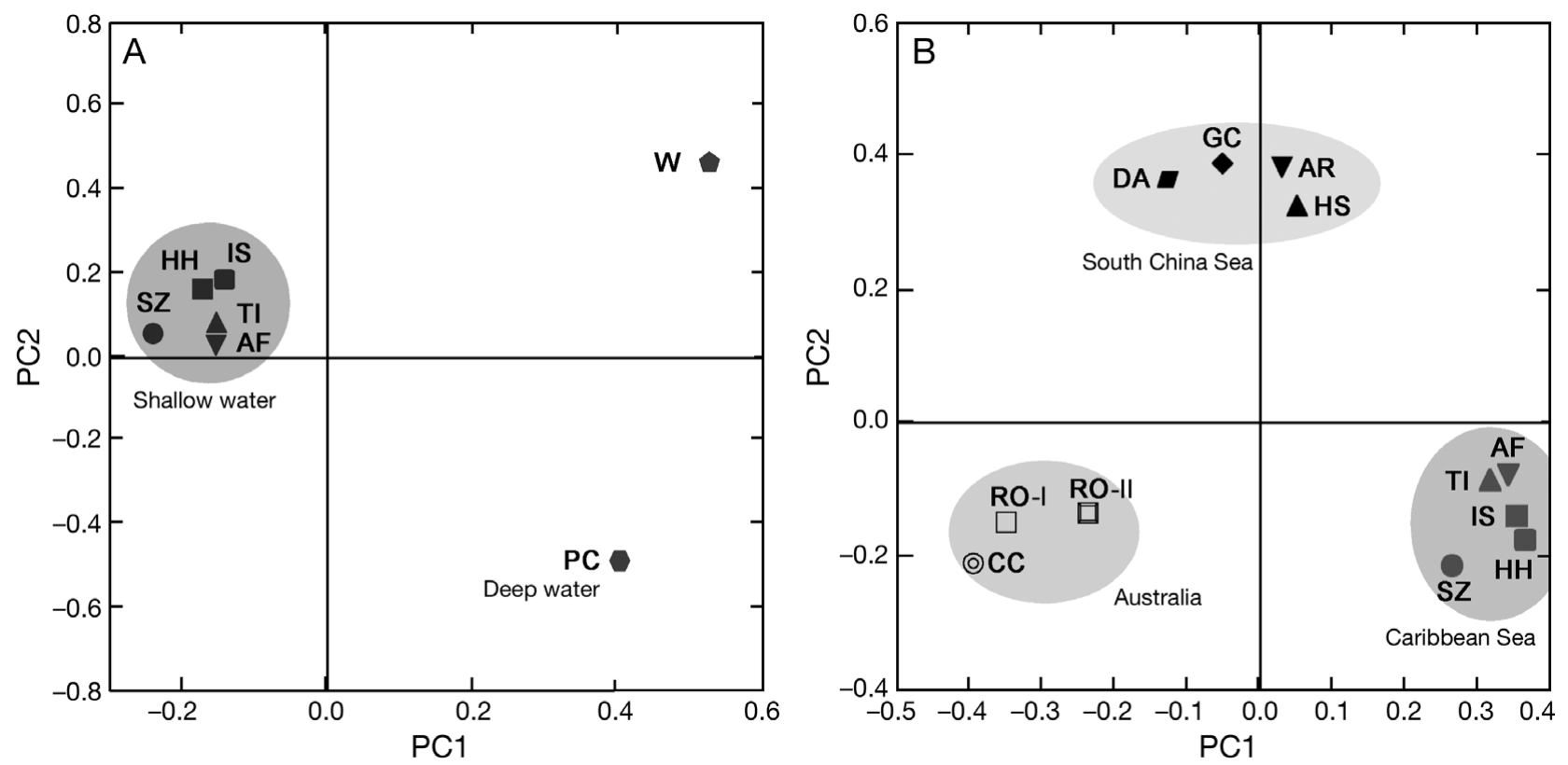

Fig. 5. Similarity of bacterial communities associated with sponges from different geographic locations and seawater from the present study based on weighted UniFrac analysis of the 16S rDNA clone sequences. The first 2 principal coordinate axes for the PCA (PC1 and PC2) and the distribution of the bacterial communities (designated by their source names) in response to these axes are shown for (A) Caribbean sponges and ambient seawater from the present study (PC1 and PC2 explained 31.08 and $20.99 \%$ of the variation, respectively) and (B) sponges from Caribbean Sea, South China Sea and Australia (PC1 and PC2 explained 24.58 and $15.65 \%$ of the variation, respectively). See Table 1 for sample definitions

and temporal scales, the bacterial communities associated with the sponges from different geographical origins were diverse, whereas sponges from the same habitat tended to contain uniform bacterial groups that clustered together (Fig. 5).

The vertical transmission of bacterial communities from the parent generation to filial sponges offers a reasonable explanation of how juvenile sponges initially accept bacterial communities, and how highly sponge-specific microbial communities are maintained (Ereskovsky et al. 2005, Maldonado 2007, Schmitt et al. $2007,2008)$. However, when sponges enter the filterfeeding life phase in early adulthood, they begin to take up seawater microbes in large quantities (Wehrl et al. 2007). In this phase, the horizontal transfer of symbionts between host individuals and the environmental acquisition of microbes from the surrounding seawater may occur (Taylor et al. 2005), resulting in symbiont dispersal among host individuals occupying the same ecological niche, thus unifying the microbial communities. In the present study, the bacterial communities associated with the sponges resident in Caribbean Sea mangroves, a relatively static type of water body, were found to be phylogenetically similar, and significantly distinct from those derived from other biogeographical sites. The interspecific variation and the distinct biogeographical characteristics that the sponge-associated bacteria exhibited indicate that the acquisition, establishment and formation of functional sponge-associated bacterial communities may initially be the product of both vertical and horizontal transmission, and is then shaped by the internal environment created by the sponge species (competition, adaptability and selectivity) and certain external environmental factors (nutrient sources and chemical and physical factors). Thus, the traits or function of bacterial communities determine their existence and richness in sponge species.

Acknowledgements. The authors thank V. Constantino, S. Zea and J. Pawlik for their help with sample collection, S. Zea for identification of sponges, and F. Lafi for his constructive comments on the manuscript. This work was supported by a grant from the CAS/SAFEA International Partnership Program for Creative Research Teams and an award (SAC0040/UK-C0016) made by King Abdullah University of Science and Technology (KAUST) to P.Y.Q.

\section{LITERATURE CITED}

Cole JR, Chai B, Marsh TL, Farris RJ and others (2003) The Ribosomal Database Project (RDP-II): previewing a new autoaligner that allows regular updates and the new prokaryotic taxonomy. Nucleic Acids Res 31:442-443

$>$ Dash S, Jin C, Lee OO, Xu Y, Qian PY (2009) Antibacterial and antilarval-settlement potential and metabolite profiles of novel sponge-associated marine bacteria. J Ind Microbiol Biotechnol 36:1047-1056 
Egan S, Holmström C, Kjelleberg S (2001) Pseudoalteromonas ulvae sp. nov., a bacterium with antifouling activities isolated from the surface of a marine alga. Int J Syst Evol Microbiol 51:1499-1504

Enticknap JJ, Kelly M, Peraud O, Hill RT (2006) Characterization of a culturable alphaproteobacterial symbiont common to many marine sponges and evidence for vertical transmission via sponge larvae. Appl Environ Microbiol 72:3724-3732

Ereskovsky AV, Gonobobleva E, Vishnyakov A (2005) Morphological evidence for vertical transmission of symbiotic bacteria in the viviparous sponge Halisarca dujardini Johnston (Porifera, Demospongiae, Halisarca). Mar Biol 146:869-875

Faulkner DJ, Harper MK, Haygood MG, Salomon CE, Schmidt EW (2000) Symbiotic bacteria in sponges: sources of bioactive substances. In: Fusetani N (ed) Drugs from the sea. Basel, Karger, p 107-119

Fieseler L, Horn M, Wagner M, Hentschel U (2004) Discovery of the novel candidate phylum 'Poribacteria' in marine sponges. Appl Environ Microbiol 70:3724-3732

Fieseler L, Quaiser A, Schleper C, Hentschel U (2006) Analysis of the first genome fragment from the marine spongeassociated, novel candidate phylum Poribacteria by environmental genomics. Environ Microbiol 8:612-624

Friedrich AB, Fischer I, Proksch P, Hacker J, Hentschel U (2001) Temporal variation of the microbial community associated with the Mediterranean sponge Aplysina aerophoba. FEMS Microbiol Ecol 38:105-115

Hardoim CC, Costa R, Araujo FV, Hajdu E and others (2009) Diversity of bacteria in the marine sponge Aplysina fulva in Brazilian coastal waters. Appl Environ Microbiol 75:3331-3343

Hentschel U, Hopke J, Horn M, Friedrich AB, Wagner M, Hacker J, Moore BS (2002) Molecular evidence for a uniform microbial community in sponges from different oceans. Appl Environ Microbiol 68:4431-4440

Hentschel U, Fieseler L, Wehrl M, Gernert C, Steinert M, Hacker J, Horn M (2003) Microbial diversity of marine sponges. In: Müller WEG (ed) Molecular marine biology of sponges. Springer Verlag, Heidelberg, p 60-88

Hentschel U, Usher KM, Taylor MW (2006) Marine sponges as microbial fermenters. FEMS Microbiol Ecol 55:167-177

Hill RT (2004) Microbes from marine sponges: a treasure trove of biodiversity for natural products discovery. In: Bull AT (ed) Microbial diversity and bioprospecting. ASM Press, Washington, DC, p 177-190

$>$ Holmström C, Egan S, Franks A, McCloy S, Kjelleberg S (2002) Antifouling activities expressed by marine surface associated Pseudoalteromonas species. FEMS Microbiol Ecol 41:47-58

Lafi FF, Fuerst AJ, Fieseler L, Engels C, Goh WWL, Hentschel U (2009) Widespread distribution of Poribacteria in Demospongiae. Appl Environ Microbiol 75:5695-5699

> Lee OO, Lau SCK, Qian PY (2006) Consistent bacterial community structure associated with the surface of the sponge Mycale adhaerens Bowerbank. Microb Ecol 52: 693-707

Lee OO, Chui PY, Wong YH, Pawlik JR, Qian PY (2009) Evidence for vertical transmission of bacterial symbionts from adult to embryo in the Caribbean sponge Svenzea zeai. Appl Environ Microbiol 75:6147-6156

Liu WT, Marsh TL, Cheng H, Forney LJ (1997) Characterization of microbial diversity by determining terminal restriction fragment length polymorphisms of genes encoding 16S rRNA. Appl Environ Microbiol 63:4516-4522

Lozupone C, Knight R (2005) UniFrac: a new phylogenetic method for comparing microbial communities. Appl Environ Microbiol 71:8228-8235

Lozupone CA, Hamady M, Kelley ST, Knight R (2007) Quantitative and qualitative diversity measures lead to different insights into factors that structure microbial communities. Appl Environ Microbiol 73:1576-1585

Maldonado M (2007) Intergenerational transmission of symbiotic bacteria in oviparous and viviparous demosponges, with emphasis on intracytoplasmically compartmented bacterial types. J Mar Biol Assoc UK 87:1701-1713

> McCarthy SA, Johnson RM, Kakimoto D (1994) Characterization of an antibiotic produced by Alteromonas luteoviolacea Gauthier 1982, 85 isolated from Kinko Bay, Japan. J Appl Bacteriol 77:426-432

Meyer B, Kuever J (2008) Phylogenetic diversity and spatial distribution of the microbial community associated with the Caribbean deep-water sponge Polymastia cf. corticata by $16 \mathrm{~S}$ rRNA, aprA, and amoA gene analysis. Microb Ecol 56:306-321

Mohamed NM, Enticknap JJ, Lohr JE, McIntosh SM, Hill RT (2008a) Changes in bacterial communities of the marine sponge Mycale laxissima on transfer into aquaculture. Appl Environ Microbiol 74:1209-1222

Mohamed NM, Rao V, Hamann MT, Kelly M, Hill RT (2008b) Monitoring bacterial diversity of the marine sponge Ircinia strobilina upon transfer into aquaculture. Appl Environ Microbiol 74:4133-4143

Müller WEG, Müller IM (2003) Origin of the metazoan immune system: identification of the molecules and their functions in sponges. Integr Comp Biol 43:281-292

Müller WEG, Grebenjuk VA, Thakur NL, Thakur AN and others (2004) Oxygen-controlled bacterial growth in the sponge Suberites domuncula: toward a molecular understanding of the symbiotic relationships between sponge and bacteria. Appl Environ Microbiol 70:2332-2341

Schirmer A, Gadkari R, Reeves CD, Ibrahim F, DeLong EF, Hutchinson CR (2005) Metagenomic analysis reveals diverse polyketide synthase gene clusters in microorganisms associated with the marine sponge Discodermia dissoluta. Appl Environ Microbiol 71:4840-4849

$>$ Schloss PD, Handelsman J (2005) Introducing DOTUR, a computer program for defining operational taxonomic units and estimating species richness. Appl Environ Microbiol 71:1501-1506

> Schmidt EW, Obraztsova AY, Davidson SK, Faulkner DJ, Haygood MG (2000) Identification of the antifungal peptide containing symbiont of the marine sponge Theonella swinhoei as a novel $\delta$-proteobacterium, 'Candidatus Entotheonella palauensis'. Mar Biol 136:969-977

Schmitt S, Weisz JB, Lindquist N, Hentschel U (2007) Vertical transmission of a phylogenetically complex microbial consortium in the viviparous sponge Ircinia felix. Appl Environ Microbiol 73:2067-2078

> Schmitt S, Angermeier H, Schiller R, Lindquist N, Hentschel U (2008) Molecular microbial diversity survey of sponge reproductive stages and mechanistic insights into vertical transmission of microbial symbionts. Appl Environ Microbiol 74:7694-7708

Sharp KH, Eam B, Faulkner DJ, Haygood MG (2007) Vertical transmission of diverse microbes in the tropical sponge Corticium sp. Appl Environ Microbiol 73:622-629

> Taylor MW, Schupp PJ, Dahllöf I, Kjelleberg S, Steinberg PD (2004) Host specificity in marine sponge-associated bacteria, and potential implications for marine microbial diversity. Environ Microbiol 6:121-130

> Taylor MW, Schupp PJ, de Nys R, Kjelleberg S, Steinberg PD (2005) Biogeography of bacteria associated with the 
marine sponge Cymbastela concentrica. Environ Microbiol 7:419-433

Taylor MW, Hill RT, Piel J, Thacker RW, Hentschel U (2007a) Soaking it up: the complex lives of marine sponges and their microbial associates. ISME J 1:187-190

Taylor MW, Radax R, Steger D, Wagner M (2007b) Spongeassociated microorganisms: evolution, ecology, and biotechnological potential. Microbiol Mol Biol Rev 71:295-347

Thakur NL, Müller WEG (2005) Sponge-bacteria association: a useful model to explore symbiosis in marine invertebrates. Symbiosis 39:109-116

Thompson JD, Gibson TJ, Pleiomiak F, Jeanmougin F, Higgnins DG (1997) The ClustalX interface: flexible strategies for multiple sequence alignment aided by quality analysis tool. Nucleic Acids Res 25:4876-4882

Usher KM, Kuo J, Fromont J, Sutton DC (2001) Vertical transmission of cyanobacterial symbionts in the marine sponge Chondrilla australiensis (Demospongiae). Hydrobiologia 461:9-13

Webster NS, Wilson KJ, Blackall LL, Hill RT (2001) Phylo-

Editorial responsibility: Jed Fuhrman,

Los Angeles, California, USA genetic diversity of bacteria associated with the marine sponge Rhopaloeides odorabile. Appl Environ Microbiol 67:434-444

Webster NS, Cobb RE, Negri AP (2008) Temperature thresholds for bacterial symbiosis with a sponge. ISME J 2:830-842

Webster NS, Taylor MW, Behnam F, Lücker S and others (2010) Deep sequencing reveals exceptional diversity and modes of transmission for bacterial sponge symbionts. Environ Microbiol 12:2070-2082

Wehrl M, Steinert M, Hentschel U (2007) Bacterial uptake by the marine sponge Aplysina aerophoba. Microb Ecol 53:355-365

> Wilkinson CR (1984) Immunological evidence for the Precambrian origin of bacterial symbioses in marine sponges. Proc R Soc Lond B Biol Sci 220:509-517

Zarzycki J, Brecht V, Müller M, Fuchs G (2009) Identifying the missing steps of the autotrophic 3-hydroxypropionate $\mathrm{CO}_{2}$ fixation cycle in Chloroflexus aurantiacus. Proc Natl Acad Sci USA 106:21317-21322

Submitted: June 8, 2010; Accepted: October 29, 2010

Proofs received from author(s): January 19, 2011 